to six and one-half inches from the point and never allowing this mark to pass the meatus.

When now the injection is to be applied to the prostatic urethra it must be conveyed through the constrictor by means of a metallic catheter, of which the best is that devised by Ultzmann. The end of this instrument should be placed just beyond the sphincter, and the fluid, when thrown in, thus washes out the prostate and flows on into the bladder, where, if non-irritating, it may be left, or from which it may be withdrawn by slightly advancing the catheter. To determine when the point of the catheter is in the prostrate is ordinarily easy to one accustomed to make these applications, for the sensation of a slight resistance at the constrictor is easily perceived, and, as soon as this is passed, the instrument is in correct position. In case of doubt, the catheter may be advanced till it draws water and then withdrawn into the prostate.

In conclusion, I would say that I have encleavored not to overstate, and do not think I have overestimated, the importance of this constrictor muscle in relation to the pathology and treatment of the inflammations of the urethra and neck of the bladder, and $I$ believe that a correct appreciation of its action is of the greatest importance for the proper application of local treatment to these diseases.

\section{REPORT OF A CASE OF MONOMANIA.1}

BY E. S. Boland, M.D.

Miss X. consulted me in September, 1883, for what she recognized as a third attack of insanity. Aged thirty-one. She is the youngest of five children. There is no insanity in the family as far as known. She is a Catholic. Naturally amiable, sociable, and intelligent. A graduate of one of the city grammar schools, she declined a proposed normal course and began to learn dressmaking with an older sister.

She is of rather slight build, but is fairly wellproportioned and has pleasing features. Her hair began to turn in her teens and is now quite gray. Menstruation began about the age of twelve, but was always scanty and the periods painful. At fourteen or fifteen there was amenorrhœa for a year or more, for which she was treated locally with some benefit. With this exception her general health has been good except during the two former attacks, which shall be referred to later.

When she presented herself she had for some years been employed as a saleswoman in a large dry-goods house. Beginning to feel unequal to her work she took a vacation, but received no permanent benefit. She complained of failing general health and inability to fix her mind on her work. She had an involuntary and irresistible impulse or conception to repeat every act, word, or thought five times. This occupied all her waking hours, to the exclusion of almost every other mental operation.

This symptom was present in both former attacks and she has learned to fear it. The first of these attacks she recovered from at home in four or five

${ }^{1}$ Read before the Boston Medico.Psychological Society, Decem. ber 18,1884 . months, the second attack lasted over a year and was recovered from in the Boston Lunatic Hospital. Along with the imperative repetition of everything in series of fives there was complete menstrual suppression and dreamless sleep. Both these symptoms had again recurred. She knew too well their significance and was in dismay at the prospect of months of suffering before her. There was some loss of flesh, poor sleep, and great mental suffering. She knows the absurdity of her counting and felt that it is a great annoyance to her family and yet she was totally helpless to resist it.

Hospital treatment was advised but was not acted on and she was treated at home. A liberal diet, wine, and rest was ordered, and iron quinine and strychnine in tonic doses was prescribed and various combinations of sedatives given for the relief of her broken sleep.

After several weeks of this treatment, no improvement could be seen. In fact she seemed to get worse. The counting continued on every occasion, the sleep was poor, appetite deficient and irregular, and from standing and debility her feet and ankles became odematous at night.

Still, her ordinary intelligence was not markedly affected, her memory was good, her hope of recovery persisted, and she was keenly aware of her unfortunate and troublesome condition. Hospital treatment was again urged. The friends would gladly have sent her to the hospital, but it was then crowded and they refused to have her sent to a State hospital. She would not go voluntarily, as she dreaded the surrender of her own way, which commitment implied. She was ordered to bed, and no evidence of heart or kidney trouble being found, the treatment before instituted was continued, both as to medicine and diet. For three months she gradually grew worse. She ate irregularly, sat up in bed, counted, and compelled the rest of the family to count, or repeat anything said or done. If she moved her hand or her body once she had to repeat the act five times. If she swallowed saliva once she had to do so five times. She had grown so persistent and noisy that she was kept in an attic room. Here, if she heard the front door closed, she would give the family no peace until it had been closed five times. When I called and took her pulse or examined her tongue she would manœuvre to have the operation repeated five times.

With failing general health the dominant idea grew stronger. She resisted noisily every effort for her care. Her toilet, her meals, her bedmaking, etc., became occasions of great trouble to her family. She wet the bed, refused food except at night, and kept an elderly aunt, who had the immediate care of her, so busy counting and repeating acts, that she was almost worn out. She opposed any disturbance or change in her clothing, etc., and grew exceedingly dirty and disagreeable-looking. The family were worn out by her exactions and the neighbors complained to the police of the noise she made.

She was conscious of her state and actually loathed it, showed mortification at being seen in such a plight, but was so inert bodily and mentally she would not try to help herself. There was no turuing against any of the family and she realized what a nuisance she was at home. 
At this time, May, 1884, a vacancy occurring in the Boston Lunatic Hospital, she was regularly committed. When told she was to go to the hospital she protested, but made less trouble than was expected. She was able to walk up to her room with some help and was put to bed.

She still counted, sat half erect in bed, and was opposed to any change in room, bed, attendants, etc. She rather protested against toilet requirement, but less so than at home; in fact, was never noisy after admission. She was rational in her talk and very grateful for what was done for her. Extra diet, tonics, and some sedatives were used, and, as soon as possible, she was made to sit up and go out, but this was not until she had been in the hospital a month. About this time her reflexes were taken, and she wanted the tests made five times. When gotten up she always sat bolt upright in her chair with a hand on each knee, and her face as set and body as motionless as an Egyptian deity in stone. To propose another place or chair was to distress her very much, and she would always protest and say : "Just wait a while till I get better."

'The tormenting fives still controlled her thoughts and actions. It differed from the self-imposed posture, phrase, or trick of the hysterical or demented patient. She realized its absurdity and regretted her submission to it, but is apparently as powerless to resist it as is the epileptic to suppress his fit or automatism. Ordinarily ladylike and stylish she was now negligent of her appearance, would not use a toothbrush and would sit or go out in a wrapper.

There was a slight general improvement for some mouths but she was all the time sensitive to any change and shrunk from notice. During October there was a gain in weight and the acne disappeared from her face and her sleep was better.

November 7 th, she suddenly felt the cloud lifted and found herself in excellent spirits. The counting was suspended and she was happy as a child. This respite lasted almost two days when she dropped back again, but not so bad as before.

At this date she has almost regained her usual weight, looks bright, talks readily and well, and goes to chapel but does not yet read or work. She begins to dream at night as is her habit in health. She still has to count some at times. She has all through this attack evinced a desire to wait rather than work for her recovery, which she seems never to have doubted would come and which we think will be complete in a few months.

The case might be regarded as simply one of hysterical mania in a girl of a degenerative type, for there has been recurrence and there is presumedly imperfect sexual development and premature gray hair, etc., but the persistence of the dominant symptom - involuntary counting - hardly admits of being classed among the well-known and shifting vageries of the hysteric. That she is wilfully indulging this freak of counting I do not believe. She does not parade it, regards it with disgust, and shows genuine pleasure at its disappearance. Viewed in any light these features of her case will strike the observer :-

Her type of constitution; three attacks of gradually increasing severity in which these three symptoms recurred: amenorrhea, dreamless sleep and imperative impulse to count in fives; mental and physical inertia ; loss of thought-control ; dread of change; hope of recovery.

\section{REPOR'T ON CARE OF THE INSANE.}

BY WALTER CHANNING, M.D.

SUICIDAL PATIENTS IN INSANE hospitals.

Dr. SAVAGE writes ${ }^{1}$ of the dread that the public have of the commission of suicide. He himself thinks that the consideration of how suicides can best be avoided in lunatic asylums should be secondary to the care of curable cases.

In the Bethlem Asylum, of which he is superintendent, from twenty to thirty per cent. of the patients are described as suicidal, on admission. If this large number were to be placed under inspection the asylum must cease to exist as one in which patients have separate rooms and are treated in a homelike way. The number of actively suicidal patients, however, probably does not exceed five per cent.

Among the most dangerous are those patients with hallucinations of hearing, those who are persecuted, or whose relations are persecuted, those with profound mental misery, etc.

'The "persecuted" man is of ten more at peace if left in a room by himself, and often, also, young, plastic girls, who will be made more suicidal by association with others. Even patients who have attempted suicide, and who come of suicidal stock, can best be relieved from the thought of suicide, " though with some risk," in single rooms.

Dr. Savage says he does not consider constant watching of benefit to the patient. Patients have often told him, that when constantly watched, they felt as if they were dared to do a thing, and naturally set themselves to work to evade their tormentors.

It doubtless gives the superintendent a feeling of security to know that a patient is constantly watched, but the chances of recovery, though attended with greater risk, will be better in single rooms.

When a patient is admitted to the Bethlem Hospital with " suicidal" against his name, Dr. Savage puts him for a few nights in strong clothes and strong sheets in a single room. He examines the patient to decide whether this is necessary, and very often he accepts the statement of the patient, that he will exercise self-control. By encouraging self-reliance the patient very generally gets well, which he believes would not be the case if he were not trusted.

\section{GERMAN IDEAS OF INSANE-ASYLUM BUILDING AND MANAGEMENT.}

Dr. Hasse, director of the insane asylum at Königslutter, in the Province of Brunswick, writes entertainingly on this subject. ${ }^{2}$

1 Constant Watching of Suicidal Cases. By George H. Savage, M D., Journal of Mental Bcience, Aprl, 1884.

2 Einlges uber Irrenaustalten. Von Med. Rath Dr. Hasse. Allg. zeitschrift 1 . Psychiatrie, 11 Band. 1 Heft. 